\title{
PEMANFAATAN POTENSI DAN SUMBER DAYA LOKAL UNTUK PENINGKATAN EKONOMI MASYARAKAT KAMPUNG ARENG LEMBANG
}

\author{
Bambang Susanto ${ }^{1}$, Nenny Hendajany ${ }^{2}$, R. Aryanti Ratnawati ${ }^{3}$, Ae Suaesih ${ }^{4}$, Henda \\ Hendawati $^{5}$, Eva Rachmawati ${ }^{6}$, Didin Saepudin ${ }^{7}$, Anita Syafariah ${ }^{8}$, Audita Setiawan', \\ Bambang Rustandi ${ }^{10}$, Hadi Ahmad Sukardi ${ }^{11}$, Erna Garnia ${ }^{12}$, Deden Rizal ${ }^{13}$, Tiktik Sartika ${ }^{14}$, \\ Wuri Handayani ${ }^{15}$, Ahmad Zulfahmi Ubaidillah ${ }^{16}$, Fitria Lilyana ${ }^{17}$, Rusmin Nuryadin ${ }^{18}$, \\ Wiwin Sukiati ${ }^{19}$, Yuli Nawangsasi ${ }^{20}$ \\ $1,2,3,4,5,6,7,8,9,10,11,12,13,14,15,16,17,18,19,20$ Universitas Sangga Buana YPKP \\ ${ }^{1}$ korespondensi : bambang.susanto@usbypkp.ac.id
}

\begin{abstract}
ABSTRAK
Selama ini kehidupan di pedesaan umumnya berjalan dengan irama yang lambat, dimana perekonomian hanya berjalan di tempat. Padahal sumber potensi sumber daya di pedesaan tidak kalah dengan perkotaan. Banyak potensi yang dapat dikembangkan dari sumberdaya setempat. Kondisi pedesaan dimana banyak ibu-ibu yang ada atau tinggal di desa tersebut perlu diarahkan untuk meningkatkan perekonomian desa. Beberapa kegiatan yang dilakukan yaitu meningkatkan motivasi usaha, memberikan gambaran beberapa jenis usaha yang memungkinkan dapat dilakukan di desa tersebut.
\end{abstract}

Kata Kunci: potensi desa, motivasi, perekonomian

\section{ABSTRACT}

So far, life in rural areas generally runs at a slow pace, where the economy is only running in place. Even though the potential resources in rural areas are not inferior to urban areas. There is a lot of potential that can be developed from local resources. Rural conditions where many women live or live in the village need to be directed to improve the village economy. Some of the activities carried out are increasing business motivation, providing an overview of several possible types of businesses that can be carried out in the village.

Keywords: village potential, motivation, economy

\section{PENDAHULUAN}

Pembangunan seyogyanya memperhatikan kondisi dan potensi lokal yang ada dan kemudian dikembangkan agar lebih optimal agar mampu meningkatkan kesejahteraan masyarakatnya.

Berdasarkan data BPS tahun 2017 menunjukkan Kabupaten Bandung Barat (KBB) menduduki posisi ke 6 se Jawa Barat dengan \% tingkat penduduk miskin terbesar yaitu sebesar $11,49 \%$. Persentase tersebut lebih besar dari rata-rata angka kemiskinan
Jawa Barat sebesar 8,71\% atau nasional sebesar $10,64 \%$.

Salah satu potensi yang dapat dimanfaatkan masyarakat di KBB untuk mengurangi kemiskinan dan atau meningkatkan kesejahteraan masyarakatnya adalah dengan memanfaatkan potensi wisata.

Salah satu wilayah wisata terkenal di KBB adalah kawasan Lembang. Model Pemberdayaan masyarakat dengan memanfaatkan potensi yang ada juga 
menjadi salah satu strategi yang dipilih Pemerintah Daerah KBB untuk mengurangi kemiskinan ketimbang hanya bentuk bantuan yang bersifat konsumtif.

Hasil survey Tim Pengabdian pada Masyarakat Fak. Ekonomi Universitas Sangga Buana pada Desa Wangunsari, Kecamatan Lembang yang sejatinya adalah daerah pertanian karena telah berkembang menjadi daerah wisata maka terjadi alih fungsi lahan yang cukup besar sehingga produktivitas hasil pertanian menurun karena semakin terbatasnya lahan. Permasalahan lainnya adalah penduduk yang pada awalnya petani atau buruh tani kemudian lebih memilih menjadi buruh bangunan dan lainnya dikota ketimbang misalnya memanfaatkan potensi lainnya yang ada seperti industri tahu disana yang kesulitan mencari tenaga kerja untuk mengembangkan usahanya meskipun menjanjikan upah yang lebih besar dari buruh dikota. Selain industri tahu terdapat peternakan sapi perah, kelinci, eduwisata teropong bintang dan yang lainnya yang telah ada di Desa Wangunsari.

Maka dari itu, tim PPM Fakultas Ekonomi berencana memanfaatkan potensi wisata dan potensi lokal yang ada dalam upaya peningkatan kesejahteraan masyarakat melalui program pengabdian pada masyarakat sebagai implementasi tri dharma perguruan tinggi mencanangkan pengabdian pada masyarakat tahun 2019 berupa pelatihan bagi beberapa kelompok masyarakat pada desa wangunsari.

Pengabdian Pada Masyarakat mempunyai tujuan yaitu Fasilitasi embrio wirausaha baru pada wilayah binaan/PPM dengan memanfaatkan potensi lokal yang ada, Pemberdayaan Ekonomi mitra melalui kemampuan pemasaran produk UMKM melalui penerapan aplikasi teknologi yang efektif, Fasilitasi peningkatan kemampuan pengelolaan usaha (produksi, keuangan, pemasaran dan SDM), Pemberdayaan ekonomi masyarakat melalui ekonomi kreatif.

\section{METODE}

Metode pendekatan yang dilakukan untuk mengatasi permasalahan mitra adalah dengan pemberdayaan masyarakat, pelatihan dan pendampingan sebagai pemanfaatan dan pengelolaan dari sumber daya lokal dan alam di Desa Wangunsari, Kecamatan Lembang. Selain itu dilakukan sosialisasi dan pelatihan tentang motivasi dan pengembangan usaha. Dosen yang terlibat sebanyak 20 orang yang dibentuk jadi beberapa tim.

Workshop yang dilaksanakan terdiri dari:

A. Program Workshop Program workshop yang dilaksanakan adalah :

1) Workshop mengenai motivasi: 
- Memberikan motivasi untuk fokus menjadi wirausaha

- Menumbuhkan mental agar bisa berjiwa wirausaha karena persaingan yang sangat ketat.

- Memotivasi untuk mengembangan bisnis UMKM

- Tidak takut gagal dan tidak takut menyerah.

2) Workshop mengenai pengembangan Usaha:

- Memberikan pengetahuaan untuk meningkatkan pendapatan.

- Mengelola Ekonomi Keluarga

- Pencatatan dan monitoring setiap kegiatan untuk menetukan ketepatan perencanaan yang telah dibuat.

Mitra yang akan diajak kerjasama dalam kegiatan ini adalah Ibu Rumah Tangga Desa Wangunsari Kecamatan Lembang.

\section{HASIL DAN PEMBAHASAN}

Pelaksanaan kegiatan pengabdian pada masyarakat dilaksanakan pada tanggal 12 Februai 2019, dengan peserta adalah Ibu Rumah Tangga, pelaksanaan kegiatannya adalah workshop yang terdiri dari:

\section{Materi 1 Motivasi}

Sesuai hasil kesepakatan dengan salah satu pengusaha yang terletak di Desa Wangunsari Kecamatan Lembang, maka workshop memberikan pengetahuan tentang pelatihan bagaimana memotivasi para ibu rumah tangga untuk bisa memperbaiki perekonomian keluarga dengan memanfaatkan potensi lokal yang ada di Lembang, dengan materi antara lain:

- Memberikan motivasi bagaimana membangun ekonomi keluarga yang di ibaratkan dengan pohon.

- Memberikan motivasi bagaimana mengatur anggaran belanja PER

- Memberikan tips bagaimana mengontrol keuangan diantaranya: Berinvestasi dengan Baik, Disiplin, membuat atau memiliki perencanaan Keuangan, dan mengontrol kebiasaan. 


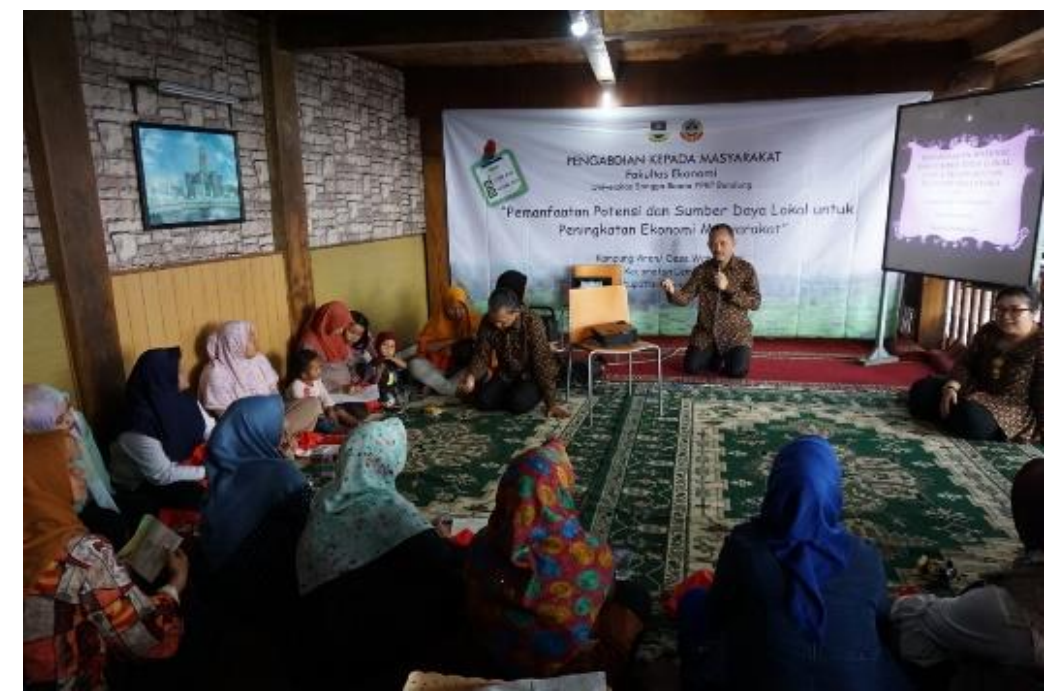

Gambar 1: Pemaparan Materi PKM tentang Motivasi oleh Dekan Fakultas Ekonomi

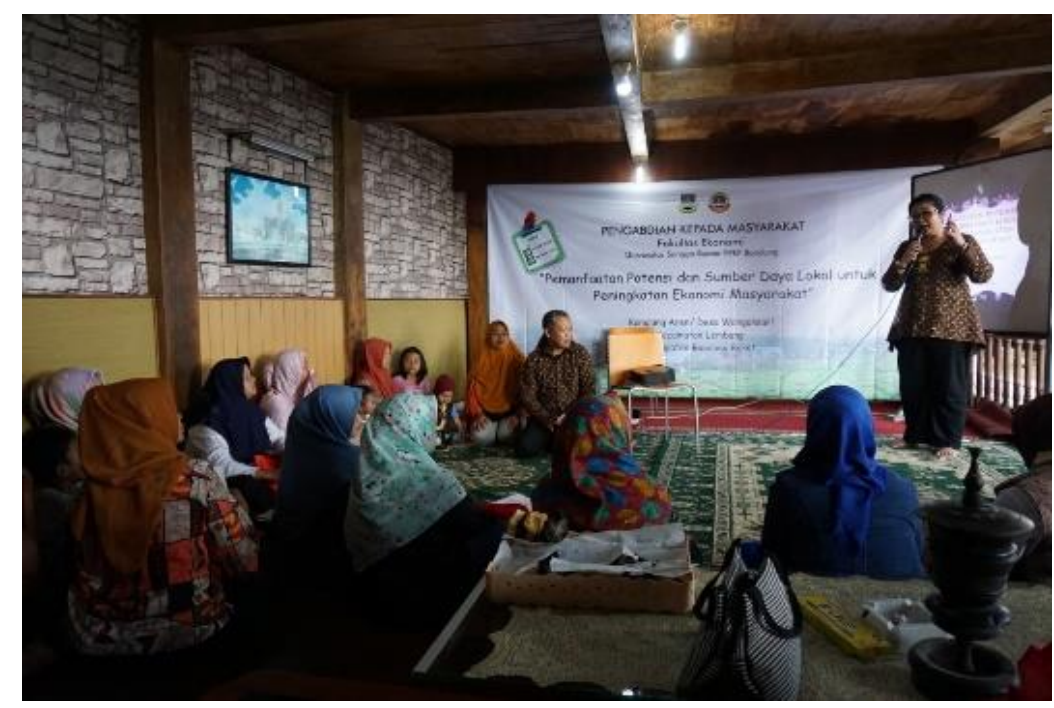

Gambar 2: Pemaparan Materi PKM tentang Motivasi oleh Pemateri (Audita Setiawan, SE., MM.)

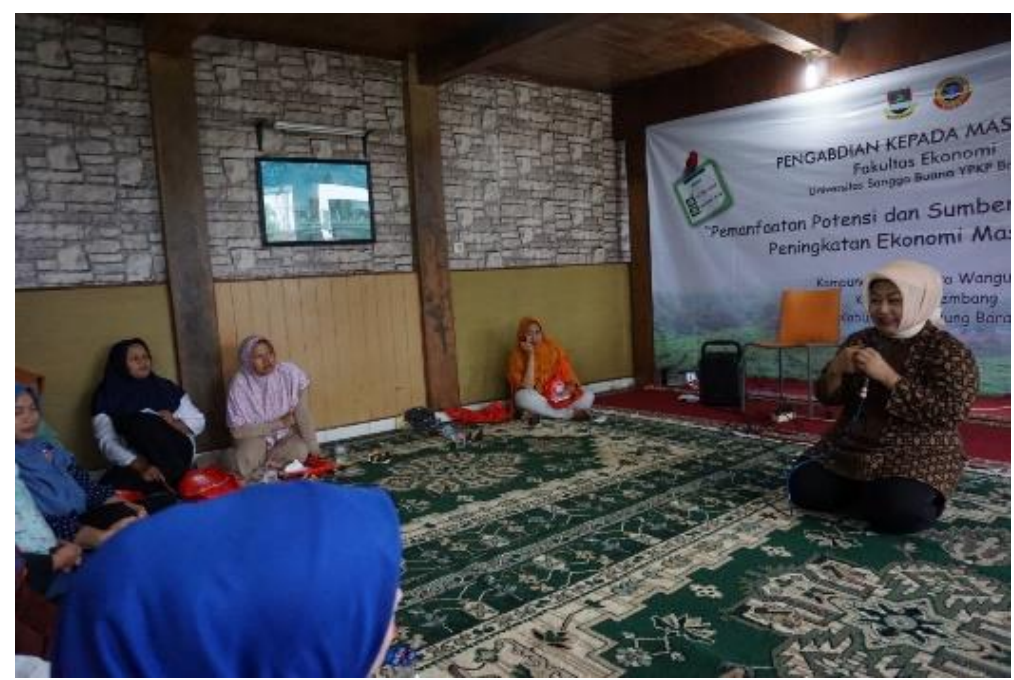

Gambar 3: Pemaparan Materi PKM tentang Motivasi oleh Pemateri (Ae Suaesih, SE., M.Si.)

Jurnal Pengabdian kepada Masyarakat USB, Volume 1 Nol bulan Mei tahun 2020.

Universitas Sangga Buana YPKP 


\section{Materi 2 Ekonomi Kreatif}

Materi Ekonomi Kreatif antara lain:

- Memberikan

gambaran

bagaimana memanfaatkan

potensi yang di miliki di daerah

Lembang dengan bahan baku yang ada.

- Terdapat beberapa unsur utama seperti kreativitas, keahlian, dan talenta yang memiliki nilai jual melalui penawaran kreasi intelektual.

- Produk yang dihasilkan (barang dan jasa) memiliki siklus hidup singkat, margin tinggi, beranekaragam, persaingan tinggi, dan dapat ditiru.

- Terdiri atas penyediaan produk kreatif langsung pada pelanggan dan pendukung penciptaan nilai kreatif pada sektor lain yang secara tidak langsung berhubungan dengan pelanggan.

- Dibutuhkan kerjasama yang baik antara berbagai pihak yang berperan dalam industri kreatif, seperti kaum intelektual, dunia usaha, dan pemerintah.

- Creative economy berbasis pada ide atau gagasan.

- Pengembangan industri kreatif tidak terbatas dan dapat diterapkan pada berbagai bidang usaha.

- Konsep creative economy yang dibangun bersifat relatif.

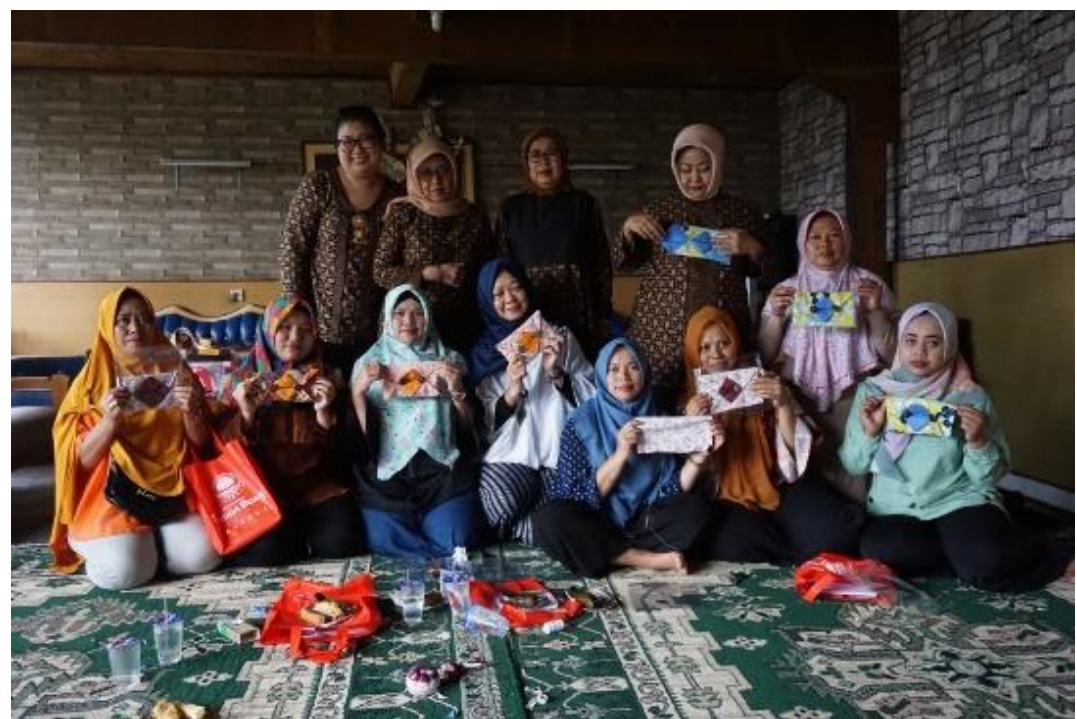

Gambar 4: Pemaparan Materi PKM tentang Ekonomi Kreatif oleh Pemateri 


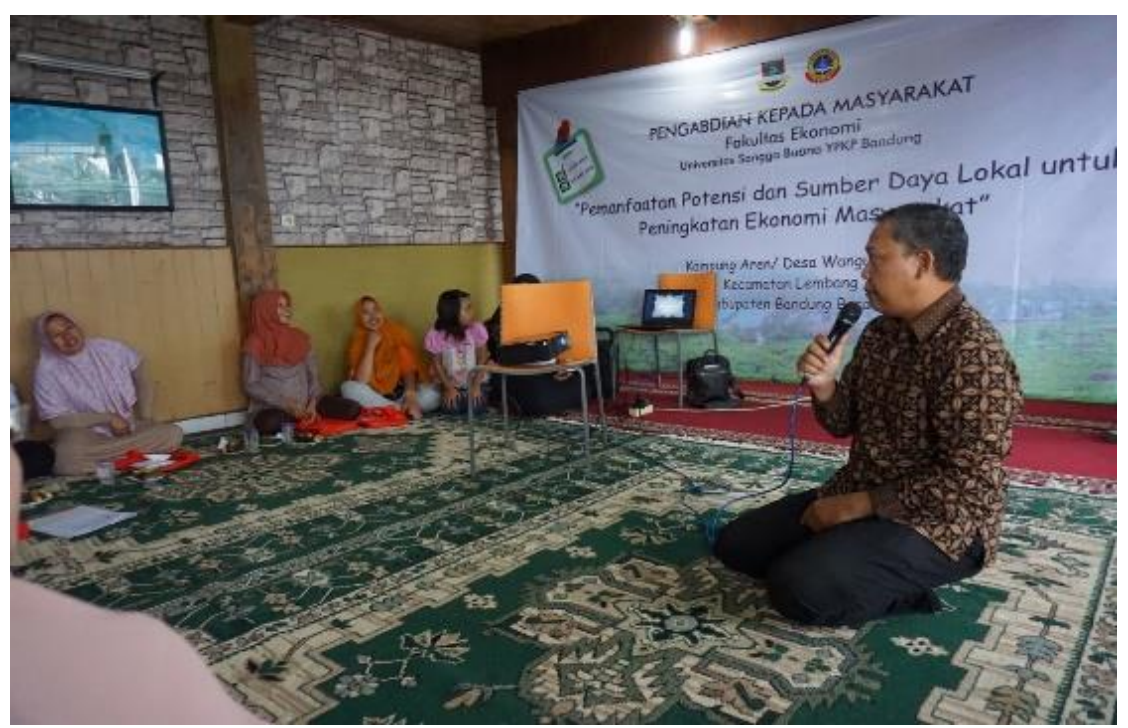

Gambar 5: Pemaparan Materi PKM tentang Ekonomi Kreatif oleh Pemateri

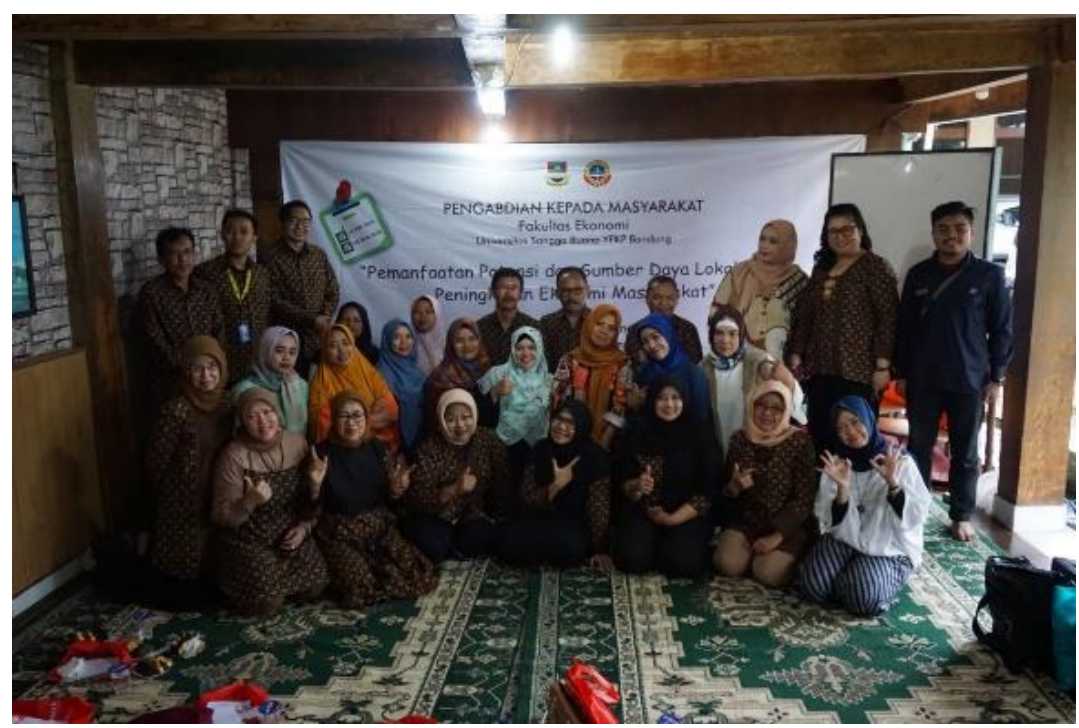

Gambar 6: Foto Bersama Panitia dan Peserta PKM

Antusias serta respon warga dinilai baik karena rasa ingin tahu yang dirasa sangat tinggi, terbujti dengan adanya kegiatan ini banyak warga yang datang mengikuti serangkaian kegiatan dari awal hingga akhir.

Secara keseluruhan pelaksanaan kegiatan dapat berjalan dnegan lancar, semua peserta aktif mengikuti pelatihan dan bersemangat untuk menindaklanjuti hasil workshop.

\section{KESIMPULAN DAN SARAN}

\section{Kesimpulan}

Pengembangan potensi desa perlu dikembangkan di Kampung Areng Lembang. Sumberdaya manusia yang perlu dikembangkan di desa ini adalah ibu-ibu yang memiliki banyak waktu luang. 
Beberapa contoh usaha diberikan untuk para ibu yang hadir agar tercipta motivasi untuk usaha

\section{Saran}

Sebaiknya pelaksanaan kegitan pengabdian seperti ini dilakukan berlanjut sampai terbinanya usaha oleh ibu-ibu di Kampung Areng Lembang.

\section{DAFTAR PUSTAKA}

[1] https://sembilanbersamamedia. wordpress.com/2012/05/30/motiv asi-bagi-pengusaha-ukm/
[2] https://berau.prokal.co/read/ news/54829-tumbuhkan-motivasiumkm.html

[3] https://jatengprov.go.id/beritadaer ah/tingkatkan-motivasipengusaha-umkm-diberipelatihan-inovasi/

[4] https://goukm.id/ekonomi-kreatif/

[5] https://www.bekraf.go.id/berita/ page/8/umkm-pegang-perananpenting-dalam-pengembanganekonomi-kreatif-asean 